\title{
Edible insects unlikely to contribute to transmission of coronavirus SARS-CoV-2
}

\author{
M. Dicke ${ }^{1}$, J. Eilenberg ${ }^{2}$, J. Falcao Salles ${ }^{3}$, A.B. Jensen ${ }^{2}$, A. Lecocq ${ }^{2}$, G.P. Pijlman ${ }^{4}$, J.J.A. van Loon ${ }^{1}$ and M.M. van Oers ${ }^{4}$ \\ ${ }^{1}$ Laboratory of Entomology, Wageningen University \& Research, P.O. Box 16, 6700 AA Wageningen, the Netherlands; \\ ${ }^{2}$ Department of Plant and Environmental Sciences, University of Copenhagen, Thorvaldsensvej 40, 1871 Frb. C., Denmark; \\ ${ }^{3}$ Microbial Community Ecology cluster, GREEN, Groningen Institute for Evolutionary Sciences (GELIFES), University of \\ Groningen, Groningen, the Netherlands; ${ }^{4}$ Laboratory of Virology, Wageningen University E Research, P.O. Box 16, 6700 AA \\ Wageningen, the Netherlands; marcel.dicke@wur.nl
}

Received: 13 May 2020 / Accepted: 26 May 2020

(c) 2020 Wageningen Academic Publishers

\section{OPEN ACCESS CC) OPINION ARTICLE}

\begin{abstract}
In the context of food safety, edible insects are evaluated for biological hazards such as microbial pathogens according to regulations currently in place. When the European Food Safety Authority evaluated the hazards of edible insects as a potential source of pathogenic viruses for humans and livestock, the novel zoonotic coronavirus SARS-CoV-2 had not yet emerged but other pathogenic coronaviruses such as SARS (SARS-CoV) and MERS (MERS-CoV) were known. As a result of the COVID-19 pandemic, animal sources of protein for human consumption are being evaluated for the risks of being a transmission vector of coronaviruses, like SARS-CoV-2. Insects lack a receptor that can bind SARS-CoV-2, thus preventing the virus from replicating in insects, unlike some vertebrate livestock species and companion animals. Despite extensive monitoring, coronaviruses have never been recorded in insect microbiomes. Contamination of insects produced for food or feed may occur during the production process, resulting from rearing substrate or from insect farmers. However, the currently permitted rearing substrates do not include animal products and the farming process is highly automated, thus limiting interactions between farmers and insects. If contamination would still occur, the fact that the insects in production are not hosts to SARS-CoV-2 precludes virus replication and the further processing of the insects will destroy the contamination. We conclude that the hazard of edible insects being a transmission vector of SARS-CoV-2 is extremely low.
\end{abstract}

Keywords: coronavirus, SARS-CoV-2, ACE2, vector, food safety

\section{Introduction}

Insects are well-established as innovative sources of sustainable animal proteins. Their production has environmental, health and food security advantages compared with production of traditional livestock. At present, the five insect species most actively produced for food and feed are the black soldier fly (Hermetia illucens), the house fly (Musca domestica), the house cricket (Acheta domesticus), the yellow mealworm (Tenebrio molitor) and the buffaloworm (Alphitobius diaperinus). The emergence of an industry producing edible insects (Van Huis, 2020) has required the development of novel legislation to regulate the production of this food source in the context of food safety. The European Food Safety Authority (EFSA) has published a comprehensive literature study to advise the
European Commission on food safety of insects as food and feed (EFSA, 2015). The hazards reviewed include biological hazards (bacteria, viruses, parasites, fungi, prions) and take into account that insects require microbiota for essential biological functions. Moreover, such biological hazards are relevant to any food source and are, thus, by default included in any food safety regulation.

The vast majority of viruses infecting insects are specific to their insect hosts and are not pathogenic to humans or other vertebrates such as livestock (EFSA, 2015). Although some insect-pathogenic viruses are phylogenetically related to viruses associated with vertebrates, these related viruses in vertebrates generally do not replicate in insects (EFSA, 2015). Some human pathogenic viruses may be transmitted passively by edible insects, although without replication 
in these insects, whereas traditional vertebrate livestock may directly host some of these viruses. Hazards of passive transmission can be mitigated through processing steps of ingoing and outgoing materials and technologies that prevent the uncontrolled movement of people and insects in production facilities. When EFSA evaluated the hazards of edible insects as a potential source of pathogenic viruses for humans or livestock (EFSA, 2015), the novel zoonotic severe acute respiratory syndrome coronavirus 2 (SARSCoV-2) had not yet emerged but other coronaviruses such as SARS-CoV and Middle East respiratory syndrome coronavirus (MERS-CoV) were known. In the context of the current coronavirus disease 2019 (COVID-19) pandemic that is caused by SARS-CoV-2, animal protein sources are being evaluated for their potential as source of infection. Therefore, we here provide specific information on the likelihood that edible insects may be a source of SARSCoV-2.

\section{Insects as vectors of human pathogens}

Insects are subjected to a variety of diseases, typically viruses, bacteria and fungi. Insect pathogenic viruses are specialised to infect insects exclusively (Maciel-Vergara and Ros, 2017). Therefore, we do not expect insect-pathogenic viruses will become a threat to humans. The same holds for specialist insect pathogenic fungi and bacteria (Eilenberg and Jensen, 2018). Insect infection by such specialised diseases may be highly relevant for insect production systems, while not being of any significance for vectoring diseases that affect human health. Viruses affecting humans generally do not affect insects and vice versa, with the exception of a specific class of arthropod-borne viruses (arboviruses) that are vectored by blood-sucking insects, where there is commonly a very strict relation between a particular virus and a specific mosquito species. Examples are dengue virus, West Nile virus and Yellow fever virus (Weaver and Reisen, 2010). However, the transfer of viruses from non-blood-feeding insects to humans will solely be passive and a dead-end road for the virus, and therefore of no significance to human health.

\section{Viruses in the microbiomes of edible insects}

Insects, like any other organism, harbour a large number of microorganisms in their bodies (Brinker et al., 2019; Gurung et al., 2019). This microbiome is known to contribute to host fitness, by influencing fertility, fecundity and growth. It therefore plays a significant role in mass rearing of insects. Relevant examples are bacterial species from potential black soldier fly competitors such as the lesser mealworm $A$. diaperinus, which repel egg deposition by black soldier flies (Zheng et al., 2013a), and the ability of insects like black soldier fly and housefly to detoxify toxic compounds and antibiotics from waste products due to genes expressed by their microbiome (Jiang et al., 2019;
Zhang et al., 2014). The type of substrate used to feed the insects also feeds back to the microbiome, determining its composition. Black soldier flies fed on complex substrates such as waste products harbour a greater diversity of fungal and bacterial communities in their gut than those fed only on simple substrates (Boccazzi et al., 2017; Zheng et al., 2013b). Despite the substrate-driven microbiome variation, black soldier fly larvae have a core bacterial community, of which 5 and $11 \%$ persists from egg and larval stages, respectively, to adulthood (Zheng et al., 2013b), suggesting that the microbiome plays an important role in host development. Despite the relevance of the microbiome for the mass production of insects, our knowledge on how feed and rearing conditions affect the insect microbiome as well as how these changes influence insect growth and performance remains quite scarce (De Smet et al., 2018).

Although most microbiome studies of insects have focused on the bacterial and fungal components of the insect microbiome, other organisms such as Archaea and viruses are expected to be present as well (Gurung et al., 2019). The latter have been studied mostly from a vector transmission or pathogenic perspective (Maciel-Vergara and Ros, 2017). In both cases, transmission usually happens horizontally, through contaminated food, and is associated with high density cultures, which is the case for the hytrosavirus, M. domestica salivary gland hypertrophy virus (Geden et al., 2008). Although less studied, there is evidence that viruses that are present at low levels in the insect host, either transiently or persistently, may be vertically transmitted (transovarially) (Cory, 2015).

RNA viruses infecting invertebrates belong to three of the four RNA virus orders: Mononegavirales (two families out of five), Nidovirales (two families out of five), and Picornavirales (two families out of five) and ten out of 37 RNA virus families, that have yet to be assigned to an order (Ryabov, 2017). The order Nidovirales is of importance here, as it comprises the vertebrate-specific family Coronaviridae, to which SARS-CoV, MERS-CoV and SARS-CoV-2 belong, as well two other families, the Mesoniviridae and Roniviridae occurring in mosquitoes and shrimps, respectively (ICTV, 2011b).

\section{Properties of SARS-CoV-2}

The causative agent of COVID-19, SARS-CoV-2 is genetically related to the coronavirus responsible for the SARS epidemic of 2002/2003 (Gorbalenya et al., 2020). Coronavirus particles are spherical, have a single positivesense RNA genome and at the surface a lipid envelope is present from which spike proteins are projected, providing a corona-like appearance in electron microscopic photographs (ICTV, 2011a). These spikes bind to cellular receptors, allowing fusion of viral and host membrane, after which the RNA genome enters the cytoplasm of the target 
cells. Replication of the viral genome requires a specialised replication-transcription complex, which is composed of viral and host proteins and associated with a network of host cell-derived membrane structures. Like all viruses with an RNA genome, coronaviruses display a high mutation rate, and this clearly increases their ability to adapt to changing circumstances (Sanjuán et al., 2010). Occasionally, a new coronavirus variant may arise with the potential to infect a new vertebrate host species.

Naturally occurring coronaviruses have zoonotic potential, meaning they can occasionally escape from an animal host and gain the ability to multiply in a human host, and may gain the ability to spread from human to human. Several coronaviruses that cause re-occurring mild diseases in the human population today (e.g. human coronavirus OC43 and NL63), may be the consequences of ancient zoonotic events. Bats are the most likely source of most human pathogenic coronaviruses (Cui et al., 2019). The MERS$\mathrm{CoV}$ that emerged in 2012 has a reservoir in dromedary camels (Haagmans et al., 2014). However, similar viral sequences have been found in a bat (reviewed by Mackay and Arden, 2015). Sequence analysis of SARS-CoV-2 (Zhou et al., 2020) revealed that it shares properties with two naturally occurring viruses, one that has been found in pangolins, small mammals occurring in Asia, and a second one detected in bats. It has been hypothesised that in the case of SARS-CoV-2 a coronavirus circulating in bats has recombined with a virus in pangolins and after some further mutations became SARS-CoV-2 (Lau et al., 2020; Zhang et al., 2020). Yet, recent molecular and phylogenetic analyses suggest that the lineage giving rise to SARS-CoV-2 originates from bats and has been transmitted to other mammalian hosts such as pangolins (Liu et al., 2020). SARS-CoV was found in palm civets sold at live-animal markets in China. Various coronavirus strains present in horseshoe bats appeared to have recombined to result in the virus found in civet cats, which then was transmitted to humans (reviewed by Luk et al., 2019).

To be able to infect a host cell, the coronavirus spike protein needs to find a perfect fit with a receptor protein on a cell and a close match with a number of intracellular proteins to allow successful infection of a cell. The spike protein of SARS-CoV-2 appears to be derived from the ancestral pangolin coronavirus with which it shares a number of critical amino acids, which allows the interaction with the angiotensin converting enzyme II (ACE2) receptor protein in the human respiratory tract (Wan et al., 2020; Zhang et al., 2020), the same receptor as used by SARS-CoV (Ge et al., 2013) and human coronavirus NL63 (Hofmann et al., 2005).

Coronaviruses typically cause respiratory symptoms and are transmitted via respiratory droplets and aerosols as a consequence of coughing and sneezing, and alternatively via contact with surfaces contaminated with infected saliva (WHO, 2020b). Coronaviruses do not use blood-feeding insects, such as mosquitoes, to spread from host to host, and unlike arthropod-transmitted viruses, coronaviruses do not naturally replicate in insects (Callaway and Cyranoski, 2020). Insects are phylogenetically very far apart from vertebrates, making the chance of effective adaptations that would allow initial interaction with cellular receptors very unlikely and the chance of successful replication in insects extremely small. Like any virus, a coronavirus can only mutate during replication. Thus, a coronavirus should first gain an initial ability to infect and replicate in an insect before it can further mutate to become a virus that spreads between insects. The absence of coronaviruses in insects is supported by large unbiased metagenomic surveys carried out on thousands of samples from very diverse insect species (e.g. Shi et al., 2016), in which a large variety of yet unknown viruses have been detected, but not a single coronavirus.

\section{Risk of SARS-CoV-2 being harboured on and in edible insects}

Viruses often require intermediate hosts before being transmitted from their primary host to humans. Bloodsucking arthropods, such as mosquitoes, have long been known to have a role in the transmission of human viruses (Weaver, 2013). SARS-CoV-2 infection in humans is not typically associated with viraemia (virus in the blood), meaning that blood-sucking insects like mosquitoes do not come in contact with the virus. Thus, the World Health Organisation (WHO) states that 'to date there has been no information nor evidence to suggest that the new coronavirus could be transmitted by mosquitoes' (WHO, 2020a).

Transmission of the virus has been reported to occur in some mammalian vertebrates and there is no proof that SARS-CoV-2 can infect species other than mammals (Callaway and Cyranoski, 2020). In fact, as of today, there is no evidence of any insect species transmitting the SARS-CoV-2 virus (Dehghani and Kassiri, 2020). The mammalian receptor that binds SARS-CoV-2, angiotensinconverting enzyme ACE2, differs among vertebrates and ACE2 receptors that are capable of binding SARS-CoV-2 are present in a limited number of vertebrate species (Qiu et al., 2020). Although insects do have angiotensinconverting enzymes, these are very different from those in humans and therefore unlikely to be able to bind to SARS-CoV-2 (Cashman et al., 2019). As a consequence, it is highly unlikely that SARS-CoV-2 can replicate in insects or that production of the black soldier fly (BSF, H. illucens), mealworms ( $T$. molitor, A. diaperinus, Zophobas morio) or crickets (A. domesticus and others) would pose a risk of infection. 
Transfer of pathogens via contaminated surfaces is another transmission route for viruses from insects to humans. The coronavirus can remain viable for a period of time on various surfaces (Casanova et al., 2010). Therefore, insect species that thrive in indoor environments such as house flies (M. domestica) and cockroaches (e.g. Blatella spp.) may be able to harbour and transfer viral particles by contact with contaminated surfaces, or with the faeces or corpses of contaminated individuals (Dehghani and Kassiri, 2020). However, inactivation of the virus is greater at high temperature and high humidity (Casanova et al., 2010; Chan et al., 2011), which are conditions common in the facilities used to rear insects for food and feed. In conclusion, there is no evidence for coronaviruses being present in insects in general and insects produced for food and feed in particular and the chance that insect cells can bind SARS-CoV-2 is highly unlikely.

\section{Industrial practices of edible insect production}

Technologies and practices to grow and process insects for food and feed include a component of viral transmission risk. Three dimensions of production can be optimised to minimise viral risks: (1) designs and technologies restricting insect movement outside of growing systems; (2) technologies minimising risks to and from insect farmers; and (3) processing steps that reduce risks of viral transmission via end-products.

Facility designs and technologies restricting the movement of insects reduce their potential as vectors outside and within a facility. Closed facilities favoured for large-scale production that are impermeable to insects are more effective at mitigating insect vectors than open facilities. Inside the facility, designs and technologies can control the movement of insects. For example, to control the movement of flying insects, some processes rely on a combination of technologies that enclose the flying phase of the animal from the moment of eclosion until expiration (Jansen $e t$ al., 2019a,b).

Insects may passively transmit viruses to insect farmers, but infections directly between operators or via contaminated surfaces are at least as likely. Hygienic practices for food and feed production, such as hygiene zones, should be applied as a matter of course. Contemporary insect production is typically designed and operated according to these principles (IPIFF, 2019). The small size and physical characteristics of insects facilitate the automation of growing and processing them. Doing so keeps human intervention in the process minimal, and consequently contact between operators can be kept to a minimum (Arsiwalla and Aarts, 2016).
The risks of viral transmission from a production facility to the public via the end-product are similar to those of other food and feed activities and are mitigated through HACCP principles. Research has found that multiple practices and technologies used to process insects result in microbial loads that are within regulatory limits (Larouche et al., 2019; Swinscoe et al., 2019). These practices should also be effective against viruses.

\section{Conclusions}

SARS-CoV-2 is a vertebrate-specific virus that infects respiratory and gut tissues that express the ACE2 receptor type that can bind the spike proteins in the viral envelope. ACE2 is expressed in most vertebrates, but not all ACE2s can be utilised by SARS-CoV-2 as receptor (Qiu et al., 2020). So far, ACE2 receptors that bind SARS-CoV-2 have only been reported for a limited number of vertebrate species (Qiu et al., 2020). Although insects also have angiotensin-converting enzymes their structure is very different from human angiotensin-converting enzymes (Cashman et al., 2019) due to their phylogenetic distance and different functions. The only two plausible modes of contamination of commercially produced edible insects in closed systems are similar to those for any domesticated animals reared for food, i.e. via their feeding substrate or via the farmers that take care of the production animals. Feeding substrates should meet with hygienic regulations but even if the feeding substrate would be contaminated with SARS-CoV-2, the virus will not be able to replicate in the insects that ingested it. Although farmers may be another source of contamination, this hazard is low due to prescribed hygienic measures in the production of edible insects and the extensive mechanisation which minimises contact between farmers and insects. Again, if contamination via farmers would occur, the virus will not be able to replicate in the insects and the processing of the insects after harvesting is likely to destroy the virus particles.

Although SARS-CoV-2 cannot replicate in insects, insects can contribute to the development of a vaccine against this virus. Insect cells can be used to produce coronavirusspike proteins that serve as vaccine candidates (Zhou et al., 2006). Yet, this absolutely does not mean that insect cells are susceptible to coronavirus infection. For this biotechnological application, a recombinant insectinfecting baculovirus is being used to express the SARSCoV-2 spike proteins in cultured moth cells (G.P. Pijlman, unpublished data). A similar system is approved and in use for the manufacturing of subunit vaccines against cervical cancer and influenza (Cox and Hashimoto, 2011; Monie et al., 2008). 
In conclusion, no examples are known of viruses from the Coronaviridae family, to which MERS-CoV, SARS-CoV, and SARS-CoV-2 belong, that are capable of infecting and replicating in insects. Contamination of edible insects produced as feed is unlikely because the insects feed on substrates of plant origin that are subject to hygienic regulation and interaction of the insects with the farmers is extremely limited. Moreover, in the unlikely case of contamination, the viruses are likely to be destroyed by processing of the harvested insects. Thus, based on current knowledge, the hazard of edible insects being a source of transmission of SARS-CoV-2 is negligible.

\section{Acknowledgements}

We have evaluated the scientific information on SARSCoV-2 until 25 May 2020. Our research has been supported by the Netherlands Organisation for Scientific Research (NWO; NWA programme, InsectFeed project, NWA.1160.18.144) and by the EU Horizon 2020 - Research and Innovation Framework Programme (Insect Doctors, MSCA-ITN-2019 Project 859850).

\section{Conflict of interest}

The authors declare no conflict of interest.

\section{References}

Arsiwalla, T. and Aarts, K.W.P., 2016. Method and system for breeding insects, using a plurality of individual crates. US Patent Bureau, patent number US2016066552 (A1). Available at: https://tinyurl. com/yaw789eg

Boccazzi, I.V., Ottoboni, M., Martin, E., Comandatore, F., Vallone, L., Spranghers, T., Eeckhout, M., Mereghetti, V., Pinotti, L. and Epis, S., 2017. A survey of the mycobiota associated with larvae of the black soldier fly (Hermetia illucens) reared for feed production. PLoS ONE 12: e0182533. https://doi.org/10.1371/journal.pone.0182533

Brinker, P., Fontaine, M.C., Beukeboom, L.W. and Salles, J.F., 2019. Host, symbionts, and the microbiome: The missing tripartite interaction. Trends in Microbiology 27: 480-488. https://doi. org/10.1016/j.tim.2019.02.002

Callaway, E. and Cyranoski, D., 2020. Why snakes probably aren't spreading the new China virus. Nature 577: 1. https://doi. org/10.1038/d41586-020-00180-8

Casanova, L.M., Jeon, S., Rutala, W.A., Weber, D.J. and Sobsey, M.D., 2010. Effects of air temperature and relative humidity on coronavirus survival on surfaces. Applied and Environmental Microbiology 76: 2712-2717. https://doi.org/10.1128/aem.02291-09

Cashman, J.S., Cozier, G.E., Harrison, C., Isaac, R.E. and Acharya, K.R., 2019. Crystal structures of angiotensin-converting enzyme from Anopheles gambiae in its native form and with a bound inhibitor. Biochemical Journal 476: 3505-3520. https://doi.org/10.1042/ bcj20190635
Chan, K.H., Peiris, J.S.M., Lam, S.Y., Poon, L.L.M., Yuen, K.Y. and Seto, W.H., 2011. The effects of temperature and relative humidity on the viability of the SARS coronavirus. Advances in Virology 2011: 734690-734690. https://doi.org/10.1155/2011/734690

Cory, J.S., 2015. Insect virus transmission: different routes to persistence. Current Opinion in Insect Science 8: 130-135. https:// doi.org/10.1016/j.cois.2015.01.007

Cox, M.M.J. and Hashimoto, Y., 2011. A fast track influenza virus vaccine produced in insect cells. Journal of Invertebrate Pathology 107: S31-S41. https://doi.org/10.1016/j.jip.2011.05.003

Cui, J., Li, F. and Shi, Z.L., 2019. Origin and evolution of pathogenic coronaviruses. Nature Reviews Microbiology 17: 181-192. https:// doi.org/10.1038/s41579-018-0118-9

Dehghani, R. and Kassiri, H., 2020. A brief review on the possible role of houseflies and cockroaches in the mechanical transmission of coronavirus disease 2019 (COVID-19). Archives of Clinical Infectious Diseases 15: e102863. https://doi.org/10.5812/ archcid. 102863

De Smet, J., Wynants, E., Cos, P., and Van Campenhout, L., 2018. Microbial community dynamics during rearing of black soldier fly larvae (Hermetia illucens) and impact on exploitation potential. Applied and Environmental Microbiology 84: e02722-17.

European Food Safety Authority (EFSA), 2015. Risk profile related to production and consumption of insects as food and feed. EFSA Journal 13: 4257. https://doi.org/10.2903/j.efsa.2015.4257

Eilenberg, J. and Jensen, A.B., 2018. Prevention and management of diseases in terrestrial invertebrates. In: Hajek, A.E. and ShapiroIlan, D.I. (eds.) Ecology of invertebrate diseases. John Wiley \& Sons, Hoboken, NJ, USA, pp. 495-526.

Ge, X.Y., Li, J.L., Yang, X.L., Chmura, A.A., Zhu, G.J., Epstein, J.H., Mazet, J.K., Hu, B., Zhang, W., Peng, C., Zhang, Y.J., Luo, C.M., Tan, B., Wang, N., Zhu, Y., Crameri, G., Zhang, S.Y., Wang, L.F., Daszak, P. and Shi, Z.L., 2013. Isolation and characterization of a bat SARS-like coronavirus that uses the ACE2 receptor. Nature 503: 535-538. https://doi.org/10.1038/nature12711

Geden, C.J., Lietze, V.U. and Boucias, D.G., 2008. Seasonal prevalence and transmission of salivary gland hypertrophy virus of house flies (Diptera: Muscidae). Journal of Medical Entomology 45: 42-51. https://doi.org/10.1093/jmedent/45.1.42

Gorbalenya, A.E., Baker, S.C., Baric, R.S., De Groot, R.J., Drosten, C., Gulyaeva, A.A., Haagmans, B.L., Lauber, C., Leontovich, A.M., Neuman, B.W., Penzar, D., Perlman, S., Poon, L.L.M., Samborskiy, D.V., Sidorov, I.A., Sola, I., Ziebuhr, J. and Coronaviridae Study Group, 2020. The species severe acute respiratory syndrome-related coronavirus: classifying 2019-nCoV and naming it SARS-CoV-2. Nature Microbiology 5: 536-544. https://doi.org/10.1038/s41564020-0695-z

Gurung, K., Wertheim, B. and Salles, J.F., 2019. The microbiome of pest insects: it is not just bacteria. Entomologia Experimentalis et Applicata 167: 156-170. https://doi.org/10.1111/eea.12768 
Haagmans, B.L., Al Dhahiry, S.H.S., Reusken, C.B.E.M., Raj, V.S., Galiano, M., Myers, R., Godeke, G.-J., Jonges, M., Farag, E., Diab, A., Ghobashy, H., Alhajri, F., Al-Thani, M., Al-Marri, S.A., Al Romaihi, H.E., Al Khal, A., Bermingham, A., Osterhaus, A.D.M.E., AlHajri, M.M. and Koopmans, M.P.G., 2014. Middle East respiratory syndrome coronavirus in dromedary camels: an outbreak investigation. The Lancet Infectious Diseases 14: 140-145. https://doi.org/10.1016/S1473-3099(13)70690-X

Hofmann, H., Pyrc, K., Van der Hoek, L., Geier, M., Berkhout, B. and Pöhlmann, S., 2005. Human coronavirus NL63 employs the severe acute respiratory syndrome coronavirus receptor for cellular entry. Proceedings of the National Academy of Sciences 102: 7988-7993. https://doi.org/10.1073/pnas.0409465102

International Committee on Taxonomy of Viruses (ICTV), 2011a. ICTV $9^{\text {th }}$ report - virus taxonomy - positive sense RNA viruses Coranaviridae. Available at: https://tinyurl.com/yd6al9bq

International Committee on Taxonomy of Viruses (ICTV), 2011b. ICTV $9^{\text {th }}$ report - virus taxonomy - positive sense RNA viruses - order Nidovirales. Available at: https://tinyurl.com/y9ocl3de

International Platform of Insects for Food and Feed (IPIFF), 2019. IPIFF guide on good hygiene practices. IPIFF, Brussels, Belgium. Available at: https://tinyurl.com/yc978kx8

Jansen, J., Lever, W. and Leushuis, R.J., 2019a. Insect tray with cover, rack for said tray, use of an assembly of said rack with at least one tray. World Intellectual Property Organisation, patent number WO2019125164 (A1). Available at: https://tinyurl.com/yaef2wcb

Jansen, J., Schol, H.A. and Jürgens, B.F., 2019b. Insect breeding device. World Intellectual Property Organisation, patent number WO2019125165 (A1). Available at: https://tinyurl.com/y9grfasn

Jiang, C.L., Jin, W.Z., Tao, X.H., Zhang, Q., Zhu, J., Feng, S.Y., Xu, X.H., Li, H.Y., Wang, Z.H. and Zhang, Z.J., 2019. Black soldier fly larvae (Hermetia illucens) strengthen the metabolic function of food waste biodegradation by gut microbiome. Microbial Biotechnology 12: 528-543. https://doi.org/10.1111/1751-7915.13393

Larouche, J., Deschamps, M.H., Saucier, L., Lebeuf, Y., Doyen, A. and Vandenberg, G.W., 2019. Effects of killing methods on lipid oxidation, colour and microbial load of black soldier fly (Hermetia illucens) larvae. Animals 9: 182. https://doi.org/10.3390/ani9040182

Lau, S.K.P., Luk, H.K.H., Wong, A.C.P., Li, K.S.M., Zhu, L., He, Z., Fung, J., Chan, T.T.Y., Fung, K.S.C. and Woo, P.C.Y., 2020. Possible bat origin of severe acute respiratory syndrome coronavirus 2 . Emerging Infectious Disease Journal 26: 1542-1547, https://doi. org/10.3201/eid2607.200092

Liu, P., Jiang, J.-Z., Wan, X.-F., Hua, Y., Li, L., Zhou, J., Wang, X., Hou, F., Chen, J., Zou, J. and Chen, J., 2020. Are pangolins the intermediate host of the 2019 novel coronavirus (SARS-CoV-2)? PLoS Pathogens 16: e1008421. https://doi.org/10.1371/journal.ppat.1008421

Luk, H.K.H., Li, X., Fung, J., Lau, S.K.P. and Woo, P.C.Y., 2019. Molecular epidemiology, evolution and phylogeny of SARS coronavirus. Infection, Genetics and Evolution 71: 21-30. https:// doi.org/10.1016/j.meegid.2019.03.001

Maciel-Vergara, G. and Ros, V.I.D., 2017. Viruses of insects reared for food and feed. Journal of Invertebrate Pathology 147: 60-75. https://doi.org/10.1016/j.jip.2017.01.013
Mackay, I.M. and Arden, K.E., 2015. MERS coronavirus: diagnostics, epidemiology and transmission. Virology Journal 12: 222. https:// doi.org/10.1186/s12985-015-0439-5

Monie, A., Hung, C.-F., Roden, R. and Wu, T.C., 2008. Cervarix: a vaccine for the prevention of HPV 16, 18-associated cervical cancer. Biologics: Targets \& Therapy 2: 97-105.

Qiu, Y., Zhao, Y.-B., Wang, Q., Li, J.-Y., Zhou, Z.-J., Liao, C.-H. and Ge, X.-Y., 2020. Predicting the angiotensin converting enzyme 2 (ACE2) utilizing capability as the receptor of SARS-CoV-2. Microbes and Infection 22: 221-225, https://doi.org/10.1016/j.micinf.2020.03.003

Ryabov, E.V., 2017. Invertebrate RNA virus diversity from a taxonomic point of view. Journal of Invertebrate Pathology 147: 37-50. https:// doi.org/10.1016/j.jip.2016.10.002

Sanjuán, R., Nebot, M.R., Chirico, N., Mansky, L.M. and Belshaw, R., 2010. Viral mutation rates. Journal of Virology 84: 9733-9748. https://doi.org/10.1128/jvi.00694-10

Shi, M., Lin, X.D., Tian, J.H., Chen, L.J., Chen, X., Li, C.X., Qin, X.C., Li, J., Cao, J.P., Eden, J.S., Buchmann, J., Wang, W., Xu, J.G., Holmes, E.C. and Zhang, Y.Z., 2016. Redefining the invertebrate RNA virosphere. Nature 540: 539-543. https://doi.org/10.1038/ nature 20167

Swinscoe, I., Oliver, D.M., Gilburn, A.S., Lunestad, B., Lock, E.J., Ornsrud, R. and Quilliam, R.S., 2019. Seaweed-fed black soldier fly (Hermetia illucens) larvae as feed for salmon aquaculture: assessing the risks of pathogen transfer. Journal of Insects as Food and Feed 5: 15-27. https://doi.org/10.3920/jiff2017.0067

Van Huis, A., 2020. Insects as food and feed, a new emerging agricultural sector: a review. Journal of Insects as Food and Feed 6: 27-44. https://doi.org/10.3920/jiff2019.0017

Wan, Y.S., Shang, J., Graham, R., Baric, R.S. and Li, F., 2020. Receptor recognition by the novel coronavirus from Wuhan: an analysis based on decade-long structural studies of SARS coronavirus. Journal of Virology 94: e00127-20. https://doi.org/10.1128/jvi.00127-20

Weaver, S.C., 2013. Urbanization and geographic expansion of zoonotic arboviral diseases: mechanisms and potential strategies for prevention. Trends in Microbiology 21: 360-363. https://doi. org/10.1016/j.tim.2013.03.003

Weaver, S.C. and Reisen, W.K., 2010. Present and future arboviral threats. Antiviral Research 85: 328-345. https://doi.org/10.1016/j. antiviral.2009.10.008

World Health Organisation (WHO), 2020a. Coronavirus disease (COVID-19) advice for the public: myth busters. WHO, Geneva, Switzerland. Available at: https://tinyurl.com/r4wnxbd

World Health Organisation (WHO), 2020b. Modes of transmission of virus causing COVID-19: implications for IPC precaution recommendations. WHO, Geneva, Switzerland. Available at: https:// tinyurl.com/y8drm3bc

Zhang, T., Wu, Q. and Zhang, Z., 2020. Probable pangolin origin of SARS-CoV-2 associated with the COVID-19 outbreak. Current Biology 30: 1346-1351. https://doi.org/10.1016/j.cub.2020.03.022 Zhang, Z.J., Shen, J.G., Wang, H., Liu, M., Wu, L.H., Ping, F., He, Q., Li, H.Y., Zheng, C.F. and Xu, X.H., 2014. Attenuation of veterinary antibiotics in full-scale vermicomposting of swine manure via the housefly larvae (Musca domestica). Scientific Reports 4: 6844. https://doi.org/10.1038/srep06844 
Zheng, L.Y., Crippen, T.L., Holmes, L., Singh, B., Pimsler, M.L., Benbow, M.E., Tarone, A.M., Dowd, S., Yu, Z.N., Vanlaerhoven, S.L., Wood, T.K. and Tomberlin, J.K., 2013a. Bacteria mediate oviposition by the black soldier fly, Hermetia illucens (L.), (Diptera: Stratiomyidae). Scientific Reports 3: 2563. https://doi.org/10.1038/srep02563

Zheng, L.Y., Crippen, T.L., Singh, B., Tarone, A.M., Dowd, S., Yu, Z.N., Wood, T.K. and Tomberlin, J.K., 2013b. A survey of bacterial diversity from successive life stages of black soldier fly (Diptera: Stratiomyidae) by using $16 \mathrm{~S}$ rDNA pyrosequencing. Journal of Medical Entomology 50: 647-658. https://doi.org/10.1603/me12199
Zhou, P., Yang, X.L., Wang, X.G., Hu, B., Zhang, L., Zhang, W., Si, H.R., Zhu, Y., Li, B., Huang, C.L., Chen, H.D., Chen, J., Luo, Y., Guo, H., Jiang, R.D., Liu, M.Q., Chen, Y., Shen, X.R., Wang, X., Zheng, X.S., Zhao, K., Chen, Q.J., Deng, F., Liu, L.L., Yan, B., Zhan, F.X., Wang, Y.Y., Xiao, G.F. and Shi, Z.L., 2020. A pneumonia outbreak associated with a new coronavirus of probable bat origin. Nature 579: 270-273. https://doi.org/10.1038/s41586-020-2012-7

Zhou, Z., Post, P., Chubet, R., Holtz, K., McPherson, C., Petric, M. and Cox, M., 2006. A recombinant baculovirus-expressed S glycoprotein vaccine elicits high titers of SARS-associated coronavirus (SARS$\mathrm{CoV}$ ) neutralizing antibodies in mice. Vaccine 24: 3624-3631. https:// doi.org/10.1016/j.vaccine.2006.01.059 
